\title{
Banach 压缩映象原理与空间的完备性表征
}

著名的 Ekeland 变分原理与 Caristi 不 动点定理与空间的完备性是等价的, 其直接 证明见文献 [1] 和 [2] 间接证明见文献 [3]. 1983 年 Borwein ${ }^{[4]}$ 指出: 在赋范空间中 Banach 压缩映象原理与空间的完备性是等 价的, 而且作者在该文中还用一个反例说明 前述结论在一般度量空间中不成立.

本文继续研究这一问题,得到以下结果.

定理 1 设 $(X, d)$ 是一度量空间,则 $X$ 完备的充分必要条件是对任意的非空有界 闭子集 $s \subset X$ 和任意的 Banach 压缩映象 $T: S \rightarrow S$, 在 $S$ 上都存在 $T$ 的不动点.

由定理 1 即得下面的结果.

定王 2 设 $(X, d)$ 为度量空间,则下 列命题等价:

(i) $X$ 完备;

(ii) Caristi 不动点定理成立;

(iii) Ekeland 变分原理成立;

(iv) 对 $X$ 的任意的非空有界闭子集 $S, S$ 上的 Banach 压缩映象必存在不动点;

(v) 对 $X$ 的任意的非空有界闭集 $S, S$ 上 的 $\Phi$ 压缩映象一定有不动点 (见文献 [5]).

我们要指出, 定理 1 的结论似乎与文献 [4] 中关于一般度量空间中 Banach 压缩映 象原理与空间的完备性不等价的结论相矛 盾. 其实不然, 因为定理 1 中的 Banach 压
缩映象只要求 $T$ 是 $X$ 的非空有界闭集上的压 缩映象, 而文献 [4] 中则要求 $T$ 为整个空间 $X$ 上的压缩映象.

下面我们举一例子, 说明文献 [4] 所给 的反例不满足定理 1 的条件.

峢. 设

$C=\left\{(x, y) \in R^{2} ; 0<x \leqslant 1, y=\sin \left(\frac{1}{x}\right)\right\}$ 易知集合 $S=\left\{\left(\frac{1}{k \pi}, 0\right), k=1,2, \cdots\right\}$ 是 $C$ 中的闭集. 定义映象 $T: S \rightarrow S$ 如下:

$$
T\left(\frac{1}{k \pi}, 0\right)-\left(\frac{1}{2 k \pi}, 0\right), k-1,2, \cdots \text {. }
$$

故 $T$ 为 $S$ 上的压缩映象，但 $T$ 在 $S$ 中无不动 点.

\section{考文 都}

[1]史树中,数学进展, 16(1987),2: 203-206.

[2] Dancs, M. et al., Acta Sci. Math., 46(1983), $381-388$.

[ 3 ] Sulivan, F., Proc. Amer. Math. Soc.,83(1981), $345-346$

[4] Borwein, J. M., Proc. Amer. Math. Soc., 87 (1983), 246-250.

[5] 张石生,许昌师专学报, 6(1987),2: 55-62.

张石生

(四川大学数学系,成制)

向淑文

（洲师范大学数学系, 费阳)

\section{对偶算子代数的某些结果}

对偶算子代数的 $X_{\theta, r}$ 性质与不变子空间 问题及算子代数的自反性和超自反性问题均
有十分密切的联系. 我们进一步讨论了这种 性质,证明了文献 [1] 中命题 1.6 和命题 1.11 